\title{
Retraction note to: A translocator protein ligand PK11195 shows antigrowth activity in human choriocarcinoma cells
}

\author{
Noriyuki Takai $^{1}$ - Naoko Kira ${ }^{1}$ - Terukazu Ishii ${ }^{1}$ Toshie Yoshida ${ }^{1}$. \\ Masakazu Nishida $^{1}$ - Yoshihiro Nishida ${ }^{1} \cdot$ Kaei Nasu $^{1} \cdot$ Masayuki Takano $^{1}$. \\ Haruna Midori ${ }^{1} \cdot$ Satoko Koga $^{1} \cdot$ Hisashi Narahara ${ }^{1}$
}

Published online: 5 July 2015

(C) International Society of Oncology and BioMarkers (ISOBM) 2015

\section{Retraction Note to: Tumor Biol. 33:1505-1510}

DOI 10.1007/s13277-012-0401-8

This article has been retracted on request of the corresponding author. The author has identified errors affecting several figure panels in which the original data were processed inappropriately such that the panels in Figure 4: "Expression of the cell cycle- and apoptosis-related proteins treated with PK11195 in choriocarcinoma cells measured by Western blot analysis. Choriocarcinoma cells were treated with PK11195, and cell lysates were harvested after
$48 \mathrm{~h}$. Western blot analysis was performed with a series of antibodies (cyclin A, cyclin D1, Bcl-2, and cleaved caspase-3). Control cells were treated with vehicle alone. The amount of protein was normalized by comparison to levels of GAPDH" do not accurately report the original data. The other authors were not involved in making these figures. We believe that the most responsible course of action is to retract below these three papers. The corresponding author, Dr. Takai, sincerely apologizes to the co-authors and the scientific community for any inconvenience that this might cause.

The online version of the original article can be found at http://dx.doi.org/ 10.1007/s13277-012-0401-8.

Noriyuki Takai

takai@oita-u.ac.jp

1 Department of Obstetrics and Gynecology, Faculty of Medicine, Oita University, 1-1 Idaigaoka, Hasama-machi, Yufu-shi, Oita 879-5593, Japan 